\title{
Screening Andean Diversity Panel Dry Bean Lines for Resistance to Bacterial Brown Spot Disease Under Field Conditions in South Africa
}

\author{
Venâncio Salegua, ${ }^{1,2, \dagger}$ Rob Melis, ${ }^{1}$ Deidré Fourie, ${ }^{2}$ Julia Sibiya, ${ }^{1}$ and Cousin Musvosvi1 \\ ${ }^{1}$ School of Agricultural, Earth and Environmental Sciences, University of KwaZulu-Natal, Scottsville 3209, Pietermaritzburg, \\ South Africa \\ ${ }^{2}$ Agricultural Research Council-Grain Crops Institute, Potchefstroom 2520, South Africa
}

\begin{abstract}
Bacterial brown spot (BBS) disease caused by Pseudomonas syringae pv. syringae is an important disease of dry bean (Phaseolus vulgaris L.), with grain yield losses of 55\% reported in South Africa. This study aimed to identify BBS disease-resistant genotypes from 415 Andean Diversity Panel (ADP) dry bean lines and 5 check cultivars under field conditions across three sites in South Africa: Warden and Middelburg under natural infestation and Potchefstroom under artificial inoculation. Plants at Potchefstroom were inoculated with $P$. syringae pv. syringae using three isolates at 21, 28, and 36 days after planting, and disease scoring was done at 7,14 , and 21 days after inoculation following a modified 1 to 9 International Centre for Tropical Agriculture (CIAT) scale. The BBS severity percentage and the area under the disease progress curve (AUDPC) were applied to quantify the reaction of bean genotypes to BBS disease. The study identified $17.2 \%$ of evaluated germplasm as resistant and

0630, ADP-0120, and ADP-0279 were selected for both high yield and resistance at Warden, whereas ADP-0038, ADP-0721, and ADP0790 were selected for both traits at Middelburg, and lastly, ADP0120 and ADP-0079 were selected for both traits at Potchefstroom. The best genotypes selected for both high yield and BBS resistance had grain yield $>1.45 \mathrm{t} \mathrm{ha}^{-1}$ across sites and $>1.85 \mathrm{t} \mathrm{ha}^{-1}$ at individual sites, and they out yielded the best-performing check cultivar $\left(1.13 \mathrm{tha}^{-1}\right)$ and the grand mean yield $\left(0.87 \mathrm{tha}^{-1}\right)$ across sites. The AUDPC had a strong negative correlation $(r=-0.55, P<0.001)$ with grain yield at Potchefstroom. Medium-seeded genotypes showed a lower AUDPC than the large-seeded genotypes, and indeterminate genotypes showed a lower AUDPC than determinate genotypes. The genotypes selected for resistance and yield can be utilized in future dry bean improvement efforts for the South African bean market.
\end{abstract} $45.3 \%$ as moderately resistant. Genotypes ADP-0592, ADP-0790, ADP-0120, and ADP-0008 were selected for both resistance and high seed yield across the three environments. Genotypes ADP-0546, ADP-
Keywords: Andean Diversity Panel (ADP) dry bean lines, correlation among related traits, reaction to BBS disease, screening
Sub-Saharan Africa is a nutritionally unstable region with reported malnutrition-related challenges (Dlamini et al. 2017), where millions of people depend on cereal-based foods that are deficient in proteins, vitamins, and several other micronutrients. Most people in the region face occasional household food shortages leading to hunger and starvation (Singh and Miklas 2015). The adoption of legumes with increased levels of proteins can boost nutritional security in the region (Singh and Miklas 2015). Dry bean (Phaseolus vulgaris L.) provides between 10 and $25 \%$ of protein and $71 \%$ of starch (Broughton et al. 2003) to the daily diet in the region (Broughton et al. 2003). The average yield in South Africa is approximately $1.40 \mathrm{t} \mathrm{ha}^{-1}$ (Dlamini et al. 2017), which is low compared with that of North America (approximately $3.00 \mathrm{t} \mathrm{ha}^{-1}$ ) (Food and Agriculture Organization of the United Nations 2014; Kimani et al. 2005).

Dry bean cultivation is affected by several biotic constraints, including bacterial brown spot (BBS), a bacterial disease that occurs worldwide, and it is particularly serious in South Africa, being present in all of the dry bean-growing regions (Muedi et al. 2015b). BBS disease has been extensively described in the United States, Brazil, and Canada (Harveson and Schwartz 2007; Singh and Schwartz 2010). The disease, caused by Pseudomonas syringae pv. syringae, is seedborne and largely affects the foliage and to a

${ }^{\dagger}$ Corresponding author: V. Salegua; salegua@ hotmail.com

Funding: Financial support was provided by Alliance for Green Revolution for Africa (grant number AGRA 2014 PASS 013) and Inyuvesi YakwazuluNatali.

The author(s) declare no conflict of interest.

Accepted for publication 18 February 2020

(C) 2020 The American Phytopathological Society smaller extent, the pods (Navarro et al. 2007). Also, it is especially severe when beans are grown in a monocropping system (Muedi et al. 2015b). It has been reported that BBS disease can cause up to $55 \%$ of yield losses where conditions are conducive to the disease (Muedi et al. 2015b; Serfontein 1994). Symptoms may initially appear as small water-saturated wounds on leaves and pods and subsequently, develop into elliptical, necrotic brown wounds encircled by a thin yellow-green border part (Kimani et al. 2005; Muedi et al. $2015 b$ ). Sources of infection include infected seed, heavy wind, contaminated farm implements, and soil (Harveson et al. 2015). Infected seed is an important way of dissemination of $P$. syringae pv. syringae (Kimani et al. 2005). Heavy wind can promote infection by helping to create wounds on plants or disperse bacteria, but wind does not provide a bacterial source to cause infection. However, rain and overhead irrigation have similarly been recognized as effective dispersion methods of $P$. syringae pv. syringae (Navarro et al. 2007). Humidity $>95 \%$ and temperatures between 28 and $32^{\circ} \mathrm{C}$ are favorable conditions for BBS disease, and these conditions are common in the central and eastern regions of South Africa, where dry beans are widely gown on a commercial scale (Muedi et al. 2015b).

BBS disease control includes planting of certified disease-free seed, crop rotation, resistant cultivars, and control on host plants (Navarro et al. 2007). Resistant cultivars have been recognized as the best way to control the disease in a sustainable way (Harveson et al. 2015). An important study of the inheritance of BBS resistance was undertaken by Navarro et al. (2007). This research used the $P$. syringae pv. syringae seedling stem inoculation in a dry beansegregating recombinant inbred lines (RIL) population of the cross Belneb RR-1 $\times$ A55 and found a number of genomic regions situated on several linkage groups that were related to BBS resistance (Navarro et al. 2007). The large-seeded dry and green bean cultivars originating from the Andean gene pool are highly susceptible to BBS disease, whereas the small- and medium-seeded cultivars of Mesoamerican gene pool origin are more tolerant to bacterial disease (Singh and Schwartz 2010). The identification of genetic resources resistant 
to BSS disease will assist in the development of cultivars with improved resistance to BBS to the benefit of South African farmers. This study aimed to screen 415 Andean Diversity Panel (ADP) dry bean lines and 5 checks cultivars for resistance to BBS disease under field conditions in South Africa.

\section{Materials and Methods}

Genetic materials and experimental sites. In total, 415 ADP dry bean lines and 5 check cultivars maintained by the Agricultural Research Council-Grain Crops Institute Program were included in the study. The ADP consisted of genotypes from the Andean gene pool, local commercial cultivars, breeding lines, and landraces from Africa and the Americas (Cichy et al. 2015). These materials were screened for resistance to BBS disease under artificial inoculation at Potchefstroom and under natural inoculation at Warden and Middelburg during the 2017/2018 growing season. The trials were planted on 18, 19, and 20 December 2017 at Middelburg, Warden, and Potchefstroom, respectively. Potchefstroom is located in North West province of South Africa at an altitude of $1,349 \mathrm{~m}$, latitude $26.74^{\circ} \mathrm{S}$, and longitude $27.08^{\circ} \mathrm{E}$. Warden is located in Free State province, and it is at an altitude of $1,720 \mathrm{~m}$, latitude $28.31^{\circ} \mathrm{S}$, and longitude $29.12^{\circ} \mathrm{E}$. Middelburg is located in Mpumalanga province at an altitude of $1,277 \mathrm{~m}$, latitude $31.47^{\circ} \mathrm{S}$, and longitude $25.03^{\circ} \mathrm{E}$ (Muedi et al. 2015b).

Weather data. The weather data across three experimental sites are indicated in Table 1 . The mean temperatures ranged from $25.0^{\circ} \mathrm{C}$ (Warden) to $28.2^{\circ} \mathrm{C}$ (Middelburg), whereas Middelburg had the lowest rainfall $(346.34 \mathrm{~mm})$, and Warden had the highest rainfall $(687.7 \mathrm{~mm})$.

Experimental design. The experimental layout was an $\alpha$-lattice design with three replicates, with 10 incomplete blocks in each replicate at all of the three locations. The replications were separated by a 5-mwide block planted with the susceptible cultivar Teebus RR-1 as the spreader and source of inoculum. Each incomplete block had 42 plots with ADP lines, and the blocks were separated by a 2-m pathway. Each plot had one row of $5 \mathrm{~m}$ in length. Each row had 75 plants, with in-row distance of $7.5 \mathrm{~cm}$ and interrow distance of $76 \mathrm{~cm}$. Two border rows (Teebus RR-1) were planted around the four sides of the experiment, and the trial was weeded mechanically. Irrigation was applied at Potchefstroom when required, whereas Middelburg and Warden were dry land. The nitrogen, phosphorus, and potassium fertilizers were applied to the fields at rates of $42.3,22.3$, and $18.4 \mathrm{~kg} \mathrm{ha}^{-1}$, respectively.

BBS disease inoculation. Middleburg and Warden have a history of BBS disease, and the experiments relied on natural inoculation, whereas at Potchefstroom, artificial inoculum of $P$. syringae pv. syringae was applied. The inoculum was made from 48- to 72-hold cultures grown on King's B medium (Johnsen and Nielsen 1999). Three isolates (BV 6.3, BV 3.3.2, and BV 27.1) with the highest level of aggression based on bean pod assays were mixed and suspended in water for inoculation. The suspension was adjusted to $1 \times$ $10^{8} \mathrm{CFU} / \mathrm{ml}$, and it was used immediately for the field inoculation (Muedi et al. 2015a). To increase the development of BBS, the experiment was irrigated before the inoculum application on the leaves, and plants were spray inoculated at 21,28 , and 36 days after planting through a mechanical inoculum sprayer (Stihl Mist Blower SR 430) during the morning hours.

Data collection. The BBS severity was evaluated 7 days after the initial inoculation or initial appearance of disease symptoms, and the rating was done weekly for 3 consecutive weeks (Muedi et al. $2015 b$ ). The BBS severity was evaluated based on the percentage of diseased leaf area for the total plot using a modified International Centre for Tropical Agriculture (CIAT) scale from 1 (resistant or immune) to 9 (very susceptible or diseased) (van Schoonhoven and Pastor-Corrales 1987). The BBS severity scores were converted to percentages using log transformation as follows: $1=5 \%, 2=15 \%$, $3=25 \%, 4=35 \%, 5=45 \%, 6=55 \%, 7=65 \%, 8=75 \%$, and $9=$ $85 \%$. The BBS severity percentages were used to calculate the area under disease progress curve (AUDPC) (Muedi et al. 2015b). Several other traits were measured, namely days to flowering (DF), days to maturity (DM), and grain yield. The growth habit and seed size were the secondary data. The DF, DM, and grain yield data were collected from the experiments across three evaluated sites, whereas the seed size and the growth habit data were obtained through the secondary data.

Data analysis. The data were analyzed using unbalanced analysis of variance in Genstat 18th edition (Gilmour et al. 2015). Means were separated by the least significant difference (LSD) at $P=0.05$. The model for the combined analysis of variance of multienvironment trials (equation 1) was

$$
Y_{i j k l}=\mu+G_{i}+E_{j}+R_{k(j)}+B_{l(j k)}+G E_{i j}+\varepsilon_{i j k l}
$$

where $Y_{i j k l}$ is the response of the $i$ th genotype in the $j$ th environment, the $k$ th replication within the environment, and the $l$ th incomplete block within the replication; $\mu$ is the grand mean; $G_{i}$ is the effect of the $i$ th genotype, $i=1,2, \ldots, 420 ; E_{j}$ is the effect of the $j$ th environment, $j=1,2,3 ; R_{k(j)}$ is the replication effect $k=1,2,3 ; B_{l(j k)}$ is the block effect $l=1,2, \ldots, 10 ; G E_{i j}$ is the genotype $\times$ environment interaction effect; and $\varepsilon_{i j k l}$ is the random error. The relationship between BBS reaction, growth habit, and seed size was performed using the secondary data and the primary data of the AUDPC.

Disease reaction and AUDPC. The AUDPC for each genotype was calculated using the percentage severity scores as a dependent variable (Campbell and Madden 1990), and it was calculated as follows:

$$
\mathrm{AUDPC}=\sum_{i=1}^{n}\left[\left(X_{i+1}+X_{i}\right) / 2\right] \times\left[t_{i+1}-t_{i}\right]
$$

where $X_{i}$ is the disease severity rating (percentage) at date $i ; X_{i+1}$ is the disease severity rating (percentage) at date $i+1 ; t_{i+1}-t_{i}$ is the number of days between the $i$ th and the $(i+1)$ th date; and $n$ is the total number of observations.

The AUDPC data were subjected to analysis of variance, and means were separated using Fischer's LSD $(P \leq 0.05)$. Furthermore, the correlation analysis between reaction to BBS, DF, DM, AUDPC, and grain yield was performed for the Potchefstroom evaluation trial.

\begin{tabular}{|c|c|c|c|c|c|c|}
\hline \multirow[b]{2}{*}{ Month } & \multicolumn{2}{|c|}{ Potchefstroom } & \multicolumn{2}{|c|}{ Warden } & \multicolumn{2}{|c|}{ Middelburg } \\
\hline & Temperature $\left({ }^{\circ} \mathrm{C}\right)$ & Rainfall (mm) & Temperature $\left({ }^{\circ} \mathrm{C}\right)$ & Rainfall (mm) & Temperature $\left({ }^{\circ} \mathrm{C}\right)$ & Rainfall (mm) \\
\hline October 2017 & 26.39 & 56.13 & 24.89 & 49.53 & 24.90 & 28.45 \\
\hline November 2017 & 29.12 & 69.34 & 27.05 & 82.04 & 29.30 & 19.56 \\
\hline December 2017 & 29.29 & 62.48 & 26.06 & 208.79 & 32.01 & 10.03 \\
\hline January 2018 & 31.04 & 47.24 & 28.39 & 110.49 & 32.74 & 111.51 \\
\hline February 2018 & 27.68 & 68.33 & 26.75 & 66.80 & 30.68 & 77.47 \\
\hline March 2018 & 27.54 & 58.93 & 23.63 & 131.52 & 29.21 & 22.10 \\
\hline April 2018 & 25.33 & 35.56 & 22.90 & 12.95 & 24.75 & 62.74 \\
\hline May 2018 & 22.78 & 11.28 & 20.32 & 25.65 & 21.61 & 14.48 \\
\hline Average & 27.40 & - & 25.00 & - & 28.15 & - \\
\hline Total & - & 409.29 & - & 687.77 & - & 346.34 \\
\hline
\end{tabular}

Table 1. The weather data of three experimental sites ${ }^{\mathrm{a}}$

a The source of the data is the Agricultural Research Council (2018). 


\section{Results}

Combined analysis of variance across three sites. The combined analysis of variance for BBS severity and grain yield (tons hectare ${ }^{-1}$ ) is presented in Table 2 . The mean squares for genotype, environment, genotype and environment interaction (GEI) were significant $(P<$ 0.001 ) for both BBS severity and grain yield (tons hectare ${ }^{-1}$ ). The variation for BBS severity was partitioned for environment, genotype, and GEI as 4.32, 28.08, and $49.29 \%$ of the total sum of squares, respectively, whereas for grain yield (tons hectare ${ }^{-1}$ ), the variation for BBS severity was partitioned for environment, genotype, and GEI as $20.92,24.93$, and $44.95 \%$, respectively. The mean BBS severity and yield were $38.85 \%$ and $0.87 \mathrm{t} \mathrm{ha}^{-1}$, respectively. Significant GEI effects for BBS disease $(P<0.001)$ and grain yield $(P<$ 0.001 ) indicated different rankings in each environment, and thus, further analysis was done to establish which genotypes performed better or worse in particular environments.

Analysis of variance for individual sites. The analysis of variance for BBS severity and grain yield (tons hectare ${ }^{-1}$ ) for the individual sites is presented in Table 3 . There were significant differences $(P$ $<0.05$ ) among genotypes for BBS severity, AUDPC, and grain yield (tons hectare $^{-1}$ ) at three sites (Table 3). Genotype variations for BBS severity were $73.23,69.86$, and $72.80 \%$ of the total sum of squares in Warden, Middelburg, and Potchefstroom, respectively. However, genotype variations for grain yield were $86.68,84.66$, and $84.47 \%$ of the total sum of squares in Warden, Middelburg, and Potchefstroom, respectively. The genotype variation for AUDPC was $72.80 \%$ of the total sum of squares at Potchefstroom (Table 3). The variations for the blocks were $4.39,20.61$, and $10.54 \%$ for BBS severity and 1.94 ,

Table 2. Combined analysis of variance showing mean squares for bacterial brown spot (BBS) severity and grain yield across three experimental sites ${ }^{\mathrm{a}}$

\begin{tabular}{lrrrrrr}
\hline & & \multicolumn{3}{c}{ BBS severity } & & \multicolumn{2}{c}{ Yield (t ha $\mathbf{~}^{-\mathbf{1}}$ ) } \\
\cline { 3 - 4 } \cline { 6 - 7 } Source & \multicolumn{1}{c}{ DF } & \multicolumn{1}{c}{ SS } & \multicolumn{1}{c}{ MS } & & SS & MS \\
\hline Environment & 2 & $37,248.18$ & $18,624.09^{\mathrm{b}}$ & & 179.05 & $89.52^{\mathrm{b}}$ \\
Env.Rep & 6 & $1,945.12$ & $324.19^{\mathrm{b}}$ & 0.33 & $0.06^{\mathrm{c}}$ \\
Env.Rep.Block & 81 & $119,435.95$ & $1,327.07^{\mathrm{b}}$ & 47.13 & $0.52^{\mathrm{b}}$ \\
Genotypes & 419 & $241,983.45$ & $587.34^{\mathrm{b}}$ & 213.42 & $0.52^{\mathrm{b}}$ \\
Genotype $\times$ environment & 838 & $347,444.15$ & $421.66^{\mathrm{b}}$ & 358.07 & $0.44^{\mathrm{b}}$ \\
Residual & 2,433 & $113,829.28$ & 46.05 & 57.96 & 0.02 \\
Total & 3,779 & $861,886.28$ & 226.45 & 855.96 & 0.23 \\
LSD & & & 10.86 & & 0.25 \\
CV & & & 17.03 & & 17.63 \\
Mean & & & 39.85 & & 0.87 \\
\hline
\end{tabular}

${ }^{a}$ Yield indicates the grain yield (tons hectare ${ }^{-1}$ ). CV, percentage coefficient of variation; DF, days to flowering; LSD, least significant difference; MS, mean of square; SS, sum square; Env.Rep, replications within environments; Env. Rep.Block, incomplete blocks within replications and environments.

b $P<0.001$.

c $P<0.01$.
10.71 , and $7.12 \%$ for grain yield of total sum square in Warden, Middelburg, and Potchefstroom, respectively. The variations for the replication were $0.63,0.06$, and $0.18 \%$ for BBS severity and $0.09,0.02$, and $0.04 \%$ for grain yield in Warden, Middelburg, and Potchefstroom, respectively. The AUDPC variation were 10.54 for block and 0.18 for replication of total sum square.

Mean of BBS severity and grain yield across three sites. The mean BBS severity and grain yield of the 10 best-performing genotypes and the 5 worst-performing genotypes across three environments are presented in Table 4. The mean BBS severity ranged from 15 (ADP-0592) to 63.15\% (ADP-0310), whereas the grain yield of genotypes ranged from $0.32 \mathrm{t} \mathrm{ha}^{-1}$ (ADP-0577) to 1.66 $\mathrm{tha}^{-1}$ (ADP-0097). Four genotypes of the 10 best-performing genotypes, namely ADP-0592, ADP-0790, ADP-0120, and ADP-0008, had both low BBS severity and high grain yield across the three environments (Table 4). Genotypes selected across three sites had a mean grain yield above the grand mean $\left(0.87 \mathrm{t} \mathrm{ha}^{-1}\right)$ and the bestperforming local check cultivar Kamiesberg $\left(1.13 \mathrm{t} \mathrm{ha}^{-1}\right)$ and a mean BBS severity below the grand mean $(39.85 \%)$ and the bestperforming local check cultivar (31.67\%) (Table 4).

Mean of BBS disease severity and grain yield for each site. The 10 best-performing genotypes for mean BBS severity, AUDPC, and grain yield and the 10 worst-performing genotypes at the three sites are presented in Table 5 . Genotypes with BBS severity $<25.0 \%$ in three sites were regarded as resistant to BBS disease, genotypes with BBS severity between 25.0 and $55.0 \%$ were regarded as moderate, and genotypes with BBS severity $>55.0 \%$ were regarded as susceptible to the BBS disease. As a result, 8.4, 45.3, and $46.3 \%$ of genotypes were selected as resistant, moderate, and susceptible reaction to BBS disease, respectively, in Warden. In Middelburg, $35.7 \%$ of genotypes showed a resistant reaction, whereas 35.7 and $28.7 \%$ showed moderate and susceptible reaction to BBS disease, respectively. At Potchefstroom, 7.5\% were resistant to BBS disease, and 54.9 and $37.6 \%$ were moderate and susceptible, respectively. The AUDPC ranged from 1,948.30 for ADP-0733 to 105.00 for ADP0798. The mean BBS severity rates were $44.1,36.7$, and $38.68 \%$, whereas the mean grain yields were $0.8,0.64$, and $1.16 \mathrm{t} \mathrm{ha}^{-1}$ for Warden, Middelburg, and Potchefstroom, respectively.

Relation between BBS disease reaction and grain yield. The grain yield ranged from $2.47 \mathrm{t} \mathrm{ha}^{-1}$ (ADP-0546) to $0.18 \mathrm{t} \mathrm{h}^{-1}$ (ADP-0746) in Warden, from $2.13 \mathrm{t} \mathrm{ha}^{-1}$ (ADP-0239) to 0.17 $\mathrm{t} \mathrm{ha}^{-1}$ (ADP-0644) in Middelburg, and from $2.31 \mathrm{t} \mathrm{ha}^{-1}$ (ADP-0517) to $0.16 \mathrm{t} \mathrm{ha}^{-1}$ (ADP-0242) in Potchefstroom (Table 5). The genotypes ADP-0546, ADP-0630, ADP-0120, and ADP-0279 had both low mean BBS severity and the highest grain yield of the 10 bestperforming genotypes in Warden. The genotypes ADP-0038, ADP-0721, and ADP-0790 had both low mean BBS severity and the highest grain yield of the 10 best-performing genotypes in Middelburg. Genotypes ADP-0120 and ADP-0079 had low mean BBS severity, low AUDPC, and the highest grain of the 10 best-performing

Table 3. Analysis of variance showing mean for bacterial brown spot (BBS) disease severity, relative area under disease progress curve (AUDPC), and grain yield for individual sites ${ }^{\mathrm{a}}$

\begin{tabular}{|c|c|c|c|c|c|c|c|c|c|c|c|c|c|c|c|}
\hline \multirow[b]{3}{*}{ Source } & \multirow[b]{3}{*}{ DF } & \multicolumn{4}{|c|}{ Warden } & \multicolumn{4}{|c|}{ Middelburg } & \multicolumn{6}{|c|}{ Potchefstroom } \\
\hline & & \multicolumn{2}{|c|}{ BBS severity } & \multicolumn{2}{|c|}{ Grain yield } & \multicolumn{2}{|c|}{ BBS severity } & \multicolumn{2}{|c|}{ Grain yield } & \multicolumn{2}{|c|}{ BBS severity } & \multicolumn{2}{|c|}{ AUDPC } & \multicolumn{2}{|c|}{ Grain yield } \\
\hline & & SS & MS & SS & MS & SS & MS & SS & MS & SS & MS & SS & MS & SS & MS \\
\hline Rep & 2 & $1,301.18$ & $650.59^{\mathrm{b}}$ & 0.17 & $0.09^{\mathrm{c}}$ & 246.02 & 123.01 & 0.04 & 0.02 & 397.92 & $198.96^{\mathrm{d}}$ & $175,481.00$ & $87,741.00^{\mathrm{d}}$ & 0.12 & 0.06 \\
\hline Rep.block & 27 & $10,165.99$ & 338.87 & 4.09 & $0.14^{\mathrm{b}}$ & $85,335.19$ & $2,844.51^{\mathrm{b}}$ & 23.50 & $0.78^{\mathrm{b}}$ & $23,934.77$ & $797.83^{\mathrm{b}}$ & $10,555,233.00$ & $351,841.00^{\mathrm{b}}$ & 19.54 & $0.65^{\mathrm{b}}$ \\
\hline Gen & 419 & $151,379.37$ & $367.43^{\mathrm{b}}$ & 174.4 & $0.42^{\mathrm{b}}$ & $279,982.54$ & $679.57^{\mathrm{b}}$ & 183.2 & $0.45^{\mathrm{b}}$ & $158,065.70$ & $383.65^{\mathrm{b}}$ & $69,706,972.00$ & $169,192.00^{\mathrm{b}}$ & 213.90 & $0.52^{\mathrm{b}}$ \\
\hline Residual & 811 & $43,882.54$ & 53.26 & 15.80 & 0.02 & $35,222.22$ & 42.75 & 9.90 & 0.01 & $34,724.51$ & 42.14 & $15,313,511.00$ & $18,584.00$ & 32.27 & 0.04 \\
\hline Total & 1,259 & $206,729.08$ & 163.04 & 194.4 & 0.15 & $400,785.97$ & 316.08 & 216.7 & 0.17 & $217,122.90$ & $1,71.23$ & $95,751,197.00$ & $75,514.00$ & 265.8 & 0.21 \\
\hline LSD & & & 11.70 & & 0.22 & & 10.48 & & 0.18 & & 10.40 & & 218.50 & & 0.32 \\
\hline $\mathrm{CV}$ & & & 16.54 & & 17.32 & & 17.80 & & 17.00 & & 16.78 & & 16.78 & & 17.03 \\
\hline Mean & & & 44.13 & & 0.80 & & 36.73 & & 0.65 & & 38.68 & & 812.3 & & 1.16 \\
\hline
\end{tabular}

${ }^{a}$ Grain yield is in tons hectare ${ }^{-1}$. CV, percentage coefficient of variation; DF, days to flowering; LSD, least significant difference; MS, mean of squares; SS, sum square; Rep, replications; Rep.block, incomplete blocks within replications.

b $P<0.001$.

${ }^{\mathrm{c}} P<0.05$.

d $P<0.01$. 
genotypes in Potchefstroom (Table 5). Genotypes with AUDPC < 178.0 were regarded as resistant to BBS, genotypes with AUDPC between 178.0 and 1,137.0 were regarded as moderate resistance, and genotypes with AUDPC $>1,137.0$ were regarded as susceptible to BBS disease. As a result, $7.5 \%$ of the genotypes exhibited resistance to BBS disease, whereas 54.9 and $37.6 \%$ of the genotypes showed moderate and susceptible reaction, respectively. The best local commercial cultivar or the best-performing check had mean BBS severity rates of $45.0,45.0$, and $5.0 \%$, with grain yields of $1.28,0.55$, and 1.56 $\mathrm{t} \mathrm{ha}^{-1}$ in Warden, Middelburg, and Potchefstroom, respectively. The genotypes selected for both traits had mean BBS severity below and a grain yield above the best local commercial cultivar (ADP-0798), with the exception of Potchefstroom, where the genotype selected for both (ADP-0120 and ADP-0079) had approximately the same mean BBS severity and AUDPC as the best local commercial cultivar (ADP-0798).

Table 4. The mean of bacterial brown spot (BBS) severity and grain yield of the 10 best-performing genotypes and the 5 worst-performing genotypes across three sites

\begin{tabular}{lllll}
\hline Item and ADPa & Market class & BBS severity & ADP & Market class \\
\hline The 10 best-performing genotypes & & & & Yield (t ha $\left.^{-1}\right)^{\mathbf{b}}$ \\
ADP-0592 & Red mottled & $\mathbf{1 5 . 0 0}$ & ADP-0097 & Brown \\
ADP-0790 & Red mottled & $\mathbf{1 6 . 1 1}$ & ADP-0522 & Yellow \\
ADP-0432 & Red mottled & 19.44 & ADP-0079 & Purple specific \\
ADP-0454 & Red mottled & 21.30 & ADP-0122 & Cranberry \\
ADP-0796 & Cranberry & 21.30 & ADP-0592 & Red mottled \\
ADP-0126 & Navy & 22.78 & ADP-0545 & Cranberry \\
ADP-0008 & Red mottled & $\mathbf{2 3 . 1 5}$ & ADP-0790 & Red mottled \\
ADP-0125 & White & 23.15 & ADP-0120 & Cranberry \\
ADP-0079 & Purple specific & $\mathbf{2 3 . 5 2}$ & ADP-0630 & Light red kidney \\
ADP-0120 & Cranberry & $\mathbf{2 4 . 6 3}$ & ADP-0008 & Red mottled \\
The 5 worst-performing genotypes & & & & 1.58 \\
ADP-0391 & Red kidney & 57.22 & ADP-0587 & White \\
ADP-0609 & Dark red kidney & 57.22 & ADP-0639 & Light red kidney \\
ADP-0203 & Pink & 58.33 & ADP-0310 & Cranberry \\
ADP-0652 & White kidney & 61.30 & ADP-0417 & Red kidney \\
ADP-0310 & Cranberry & 63.15 & ADP-0577 & Red mottled \\
The best check & & & & 1.55 \\
ADP-798 (cultivar Kamiesberg) & Cranberry & 31.67 & ADP-798 & Cranberry \\
\hline
\end{tabular}

a ADP, Andean Diversity Panel lines.

b Grain yield is in tons hectare ${ }^{-1}$.

c Bold indicates high-yielding lines with low disease scores.

Table 5. Mean of bacterial brown spot (BBS) severity, area under disease progress curve (AUDPC; at Potchefstroom), and grain yield of the 10 best-performing genotypes at individual sites

\begin{tabular}{|c|c|c|c|c|c|c|c|c|c|c|c|c|c|c|}
\hline \multirow[b]{2}{*}{$\begin{array}{l}\text { Level of } \\
\text { resistance }\end{array}$} & \multicolumn{4}{|c|}{ Warden } & \multicolumn{4}{|c|}{ Middelburg } & \multicolumn{6}{|c|}{ Potchefstroom } \\
\hline & ADPa & $\begin{array}{c}\text { BBS } \\
\text { severity }\end{array}$ & ADP & $\begin{array}{l}\text { Grain } \\
\text { yield }^{b}\end{array}$ & ADP & $\begin{array}{c}\text { BBS } \\
\text { severity }\end{array}$ & ADP & $\begin{array}{c}\text { Grain } \\
\text { yield }\end{array}$ & ADP & $\begin{array}{c}\text { BBS } \\
\text { severity }\end{array}$ & ADP & AUDPC & ADP & $\begin{array}{c}\text { Grain } \\
\text { yield }\end{array}$ \\
\hline \multirow{10}{*}{$\begin{array}{l}\text { The most } \\
\text { resistant and } \\
\text { high yielding }\end{array}$} & 0546 & 5.00 & 0546 & 2.47 & 0038 & 8.33 & 0239 & 2.13 & 0120 & 5.00 & 0798 & 105.00 & 0517 & 2.31 \\
\hline & 0478 & 15.00 & 0063 & 2.31 & 0551 & 8.33 & 0057 & 2.07 & 0126 & 5.00 & 0797 & 105.00 & 0554 & 2.23 \\
\hline & 0376 & 18.33 & 0120 & 2.01 & 0125 & 8.33 & 0621 & 2.05 & 0432 & 5.00 & 0716 & 105.00 & 0522 & 2.19 \\
\hline & 0279 & 18.33 & 0473 & 2.00 & 0721 & 8.33 & 0038 & 2.03 & 0716 & 5.00 & 0120 & 105.00 & 0060 & 2.17 \\
\hline & 0611 & 18.33 & 0658 & 1.99 & 0592 & 8.33 & 0522 & 2.03 & 0790 & 5.00 & 0790 & 105.00 & 0008 & 2.17 \\
\hline & 0355 & 18.33 & 0101 & 1.97 & 0790 & 8.33 & 0192 & 2.03 & 0797 & 5.00 & 0126 & 105.00 & 0120 & 2.16 \\
\hline & 0585 & 18.33 & 0673 & 1.93 & 0510 & 8.33 & 0790 & 2.03 & 0798 & 5.00 & 0432 & 105.00 & 0097 & 2.15 \\
\hline & 0767 & 18.33 & 0279 & 1.91 & 0093 & 11.67 & 0737 & 1.98 & 0125 & 6.11 & 0125 & 128.30 & 0532 & 2.13 \\
\hline & 0120 & 18.33 & 0337 & 1.90 & 0740 & 11.67 & 0721 & 1.98 & 0455 & 6.11 & 0455 & 128.30 & 0527 & 2.13 \\
\hline & 0630 & 18.33 & 0630 & 1.89 & 0035 & 11.67 & 0684 & 1.94 & 0079 & 7.22 & 0079 & 151.70 & 0079 & 2.12 \\
\hline \multirow{10}{*}{$\begin{array}{l}\text { The least } \\
\text { resistant and } \\
\text { low yielding }\end{array}$} & 0074 & 65.00 & 0730 & 0.27 & 0207 & 68.33 & 0581 & 0.19 & 0587 & 58.33 & 0587 & $1,225.00$ & 0672 & 0.29 \\
\hline & 0203 & 65.00 & 0640 & 0.26 & 0759 & 71.67 & 0481 & 0.18 & 0609 & 58.33 & 0609 & $1,225.00$ & 0479 & 0.29 \\
\hline & 0095 & 68.33 & 0531 & 0.24 & 0770 & 71.67 & 0640 & 0.18 & 0623 & 58.33 & 0623 & $1,225.00$ & 0598 & 0.29 \\
\hline & 0049 & 68.33 & 0078 & 0.24 & 0644 & 71.67 & 0207 & 0.18 & 0598 & 59.44 & 0598 & $1,248.30$ & 0459 & 0.28 \\
\hline & 0640 & 68.33 & 0639 & 0.24 & 0788 & 71.67 & 0595 & 0.18 & 0610 & 59.44 & 0610 & $1,248.30$ & 0376 & 0.28 \\
\hline & 0549 & 71.67 & 0654 & 0.24 & 0659 & 71.67 & 0379 & 0.18 & 0777 & 59.44 & 0777 & $1,248.30$ & 0280 & 0.26 \\
\hline & 0105 & 71.67 & 0681 & 0.21 & 0379 & 71.67 & 0604 & 0.18 & 0220 & 61.67 & 0220 & $1,295.00$ & 0587 & 0.25 \\
\hline & 0797 & 71.67 & 0721 & 0.20 & 0581 & 71.97 & 0765 & 0.18 & 0672 & 61.67 & 0672 & $1,295.00$ & 0190 & 0.23 \\
\hline & 0078 & 71.67 & 0549 & 0.20 & 0652 & 75.00 & 0279 & 0.17 & 0310 & 66.11 & 0310 & $1,388.30$ & 0279 & 0.17 \\
\hline & 0721 & 75.00 & 0746 & 0.18 & 0595 & 75.00 & 0644 & 0.17 & 0733 & 92.78 & 0733 & $1,948.30$ & 0242 & 0.16 \\
\hline LSD & & 11.70 & & 0.22 & & 10.48 & & 0.18 & & 10.40 & & 219.00 & & 0.32 \\
\hline Mean & & 44.13 & & 0.80 & & 36.73 & & 0.64 & & 38.68 & & 812.00 & & 1.16 \\
\hline SE & & 5.96 & & 0.11 & & 5.34 & & 0.09 & & 5.30 & & 111.00 & & 0.16 \\
\hline
\end{tabular}

a ADP, Andean Diversity Panel lines; LSD, least significant difference; SE, standard error between predicted means.

${ }^{\mathrm{b}}$ Grain yield is in tons hectare ${ }^{-1}$. 
Correlation among traits. The correlations among traits at Potchefstroom, namely the relative AUDPC, grain yield (tons hectare ${ }^{-1}$ ), $\mathrm{DF}$, and DM, of the 415 ADP dry bean genotypes are presented in Table 6 . The AUDPC was highly significant and negatively correlated with grain yield $(r=-0.55)$, DF $(r=-0.27)$, and DM $(r=$ $-0.47)$. Grain yield was highly significant and positively correlated with DF $(r=0.09)$ and DM $(r=0.33)$. DF was highly significant and positively correlated with DM $(r=0.31)$ and grain yield $(r=$ 0.09).

Relationship between morphological traits and reaction to BBS disease. The relationship between seed size, growth habit, and reaction to BBS in Potchefstroom is displayed in Figure 1. The genotypes with an indeterminate growth habit showed a lower AUDPC mean than those with a determinate growth habit (Fig. 1A). In addition, the medium-seeded genotypes showed the lower AUDPC mean compared with the large-seeded genotypes (Fig. 1B). Within the indeterminate group, there was no significant difference between large- and medium-seeded genotypes with respect to the AUDPC (Fig. 1C).

\section{Discussion}

BBS is an economically important disease to dry bean production globally. This study aimed to identify BBS disease resistance and

Table 6. Correlation between days to flowering (DF), days to maturity (DM), relative area under disease progress curve (AUDPC), and grain yield at Potchefstroom

\begin{tabular}{lrrrc}
\hline Traits & DF & DM & AUDPC & Grain yield $\left(\mathbf{t ~ h a}^{-\mathbf{1}}\right)$ \\
\hline DF & 1 & & & \\
DM & $0.31^{\mathrm{a}}$ & 1 & & \\
AUDPC & $-0.27^{\mathrm{a}}$ & $-0.47^{\mathrm{a}}$ & 1 & \\
Grain yield $\left(\mathrm{t} \mathrm{ha}^{-1}\right)$ & $0.09^{\mathrm{a}}$ & $0.33^{\mathrm{a}}$ & $-0.55^{\mathrm{a}}$ & 1 \\
\hline
\end{tabular}

a $P<0.001$. high-grain yield performance among 415 ADP dry bean lines and 5 check cultivars. The analysis of variance indicated high variability among selected genotypes for BBS disease resistance and grain yield performance both across and at individual environments.

The study revealed that $17.2 \%$ of genotypes were resistant, whereas $45.3 \%$ were moderately resistant to BBS disease. These genotypes can be useful sources of genetic resistance for future dry bean improvement for the South African bean market. The high variability among genotypes implies better selection criteria based on resistance and yield performance. The GEI was also significant, which implies rank changes on genotypic performances across different sites. Significant GEI can imply that selection of genotypes is environment specific; hence, genotypes can be selected for a particular environment.

Genotypes ADP-0592, ADP-0790, ADP-0120, and ADP-0008 were selected for both high disease resistance and high grain yield across three environments. Genotypes ADP-0546, ADP-0630, ADP-0120, and ADP-0279 were selected for both high BBS disease resistance as well as high yield in Warden. Genotypes ADP-0038, ADP-0721, and ADP-0790 were the best performing at Middelburg, whereas genotypes ADP-0120 and ADP-0079 were better performing at Potchefstroom. Genotypes selected had the mean grain yield above the grand mean $\left(0.87 \mathrm{t} \mathrm{ha}^{-1}\right)$ and the best-performing cultivar $(1.13 \mathrm{t}$ $\mathrm{ha}^{-1}$ ) and mean BBS severity below the grand mean (39.85) and the best-performing or check cultivar (31.67). These genotypes had either broad or specific adaption with lower mean BBS severity and higher grain yield than the best local commercial cultivar (ADP-0798).

The results indicated that AUDPC was significantly and negatively correlated with grain yield $(r=-0.55), \mathrm{DF}(r=-0.27)$, and DM $(r=$ $-0.47)$. The disease occurrence and severity are negatively correlated with maturity period, and the grain yield is negatively correlated with BBS disease severity of the ADP genotypes. The results from the study corroborate with findings by Muedi et al. (2015a, b), who indicated that the higher the AUDPC is, the lower the grain yield will be. The medium-seeded and indeterminate growth habit genotypes had
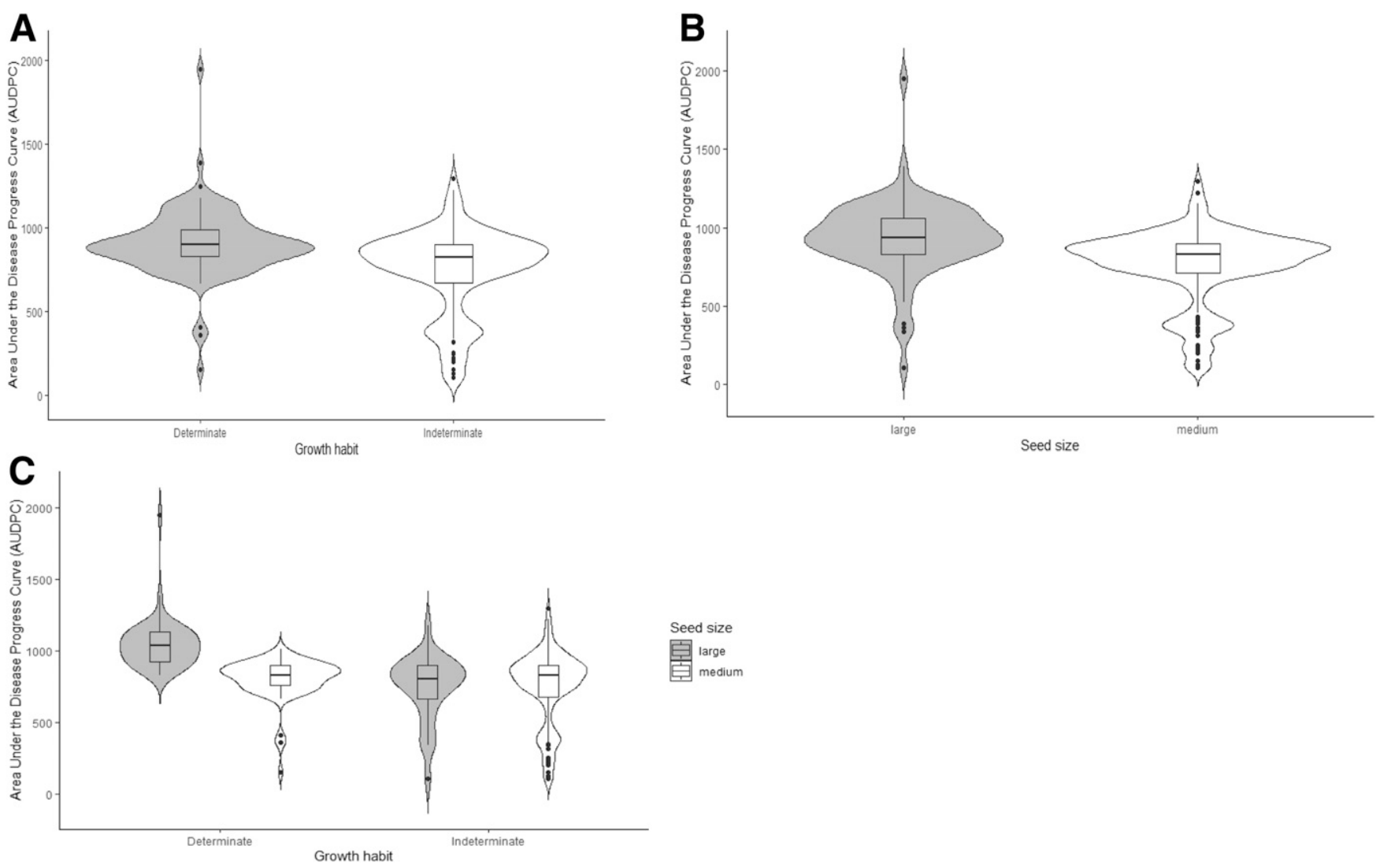

Fig. 1. Violin plots with boxplots within showing the distribution of reactions to bacterial brown spot disease (area under the disease progress curve) for Andean Diversity Panel bean genotypes grouped by growth habit and seed size. A, Distribution of reactions to the disease for genotypes grouped by growth habit, B, distribution of reactions to the disease for genotypes grouped by seed size, and C, distribution of reactions to the disease for genotypes grouped by seed class within each growth habit type. 
lower BBS severity than the large-seeded and determinate growth habit dry bean genotypes. Cichy et al. (2015) indicated that the small-seeded and indeterminate growth habit genotypes were more resistant than large-seeded and determinate growth habit genotypes on study of a dry bean diversity panel for Andean bean improvement. The medium-seeded genotypes had a lower AUDPC mean than the large-seeded dry bean genotypes. Research by Navarro et al. (2007) also reported that the seed size had an effect on resistance to the BBS disease. The genotypes with an indeterminate growth habit had lower disease severity means than those with a determinate growth habit. The suggested reason is that extended vegetative growth in indeterminate genotypes improves plant immunity. These results are similar to what Singh et al. (1991) reported in a study of genetic diversity of cultivated common bean, which included analysis of genotype reaction to common bacterial blight disease.

Several desirable ADP dry bean lines with broad adaptation were identified that had both high grain yield and low BBS disease severity, and these genotypes were regarded as potential sources of both selected traits. These genotypes could be used as donor parents in a breeding program for high yield and resistance to BBS. Four, three, and two genotypes were selected for specific adaptation for Warden, Middelburg, and Potchefstroom, respectively. These genotypes can be recommended for each specific environment. The above genotypes should be further evaluated for two or more seasons and across sites before possible release as commercial cultivars.

The study identified 17.2 and $45.3 \%$ of genotypes with resistance or moderate resistance to BBS disease, respectively. Several genotypes were adapted to specific environments. Genotypes ADP-0592, ADP0790, ADP-0120, and ADP-0008 were selected across the three environments. Genotypes ADP-0546, ADP-0630, ADP-0120, and ADP0279 were selected for both high BBS disease resistance and high yield at Warden. Genotypes ADP-0038, ADP-0721, and ADP-0790 were the best performers at Middelburg, whereas genotypes ADP-0120 and ADP-0079 were the best performers at Potchefstroom. Genotypes selected had mean grain yield above the grand and the best-performing cultivar, and they had mean BBS severity below the grand mean and the best-performing cultivar. These materials can be used as sources of resistance to BBS in future breeding programs.

\section{Acknowledgment}

We acknowledge the Agricultural Research Council-Grain Crop Improvement Breeding Program for providing seed, managing the field trials, and providing office space and technical support.

\section{Literature Cited}

Broughton, W. J., Hernandez, G., Blair, M., Beebe, S., Gepts, P., and Vanderleyden, J. 2003. Beans (Phaseolus spp.)—model food legumes. Plant Soil 252:55-128

Campbell, C. L., and Madden, L. V. 1990. Pages 187-188 in: Introduction to Plant Disease Epidemiology. John Wiley and Sons, New York, NY.

Cichy, K. A., Porch, T. G., Beaver, J. S., Cregan, P., Fourie, D., Glahn, R. P., Grusak, M. A., Kamfwa, K., Katuuramu, D. N., McClean, P., Mndolwa, E., Nchimbi-Msolla, S. Pastor-Corrales, M. A., and Miklas, P. N. 2015. A Phaseolus vulgaris diversity panel for Andean bean improvement. Crop Sci. 55:2149-2160.

Dlamini, T., Nalley, L., Tsiboe, F., Barkley, A., and Shew, A. 2017. The economic impact of the South African Agricultural Research Council's dry beans breeding program. J. Agric. Appl. Econ. 49:232-250.

Food and Agriculture Organization of the United Nations. 2014. The State of Food Insecurity in the World: Strengthening the Enabling Environment for Food Security and Nutrition. FAO, Rome, Italy.

Gilmour, A., Gogel, B., Cullis, B., Welham, S., and Thompson, R. 2015. Asreml user guide release and structural specification. VSN Int. Ltd. 4:7-9.

Harveson, R. M., and Schwartz, H. F. 2007. Bacterial diseases of dry edible beans in the Central High Plains. Plant Health Prog. 10:1093-1094.

Harveson, R. M., Schwartz, H. F., Urrea, C. A., and Yonts, C. D. 2015. Bacterial wilt of dry-edible beans in the central high plains of the US: Past, present, and future. Plant Dis. 99:1665-1677.

Johnsen, K., and Nielsen, P. 1999. Diversity of Pseudomonas strains isolated with King's B and Gould's S1 agar determined by repetitive extragenic palindromicpolymerase chain reaction, 16S rDNA sequencing and Fourier transform infrared spectroscopy characterisation. FEMS Microbiol. Lett. 173:155-162.

Kimani, P., Buruchara, R., Ampofo, K., Pyndji, M., Chirwa, R., and Kirkby, R. 2005. Breeding beans for smallholder farmers in eastern, central, and southern Africa: Constraints, achievements, and potential. PABRA Millennium Workshop 2:10-11.

Muedi, H. T. H., Fourie, D., and McLaren, N. W. 2015a. Distribution and severity of bacterial brown spot on dry beans in South Africa: An update. S. Afr. J. Sci. 111:1-6.

Muedi, H. T. H., Fourie, D., and McLaren, N. W. 2015b. Reaction of selected common bean germplasm accessions to bacterial brown spot in South Africa. Crop Prot. 77:87-93.

Navarro, F., Skroch, P., Jung, G., and Nienhuis, J. 2007. Quantitative trait loci associated with bacterial brown spot in Phaseolus vulgaris L. Crop Sci. 47: 1344-1353.

Serfontein, J. 1994. Occurrence of bacterial brown spot of dry beans in the Transvaal province of South Africa. Plant Pathol. 43:597-599.

Singh, S. P., Gutierrez, J., Molina, A., Urrea, C., and Gepts, P. 1991. Genetic diversity in cultivated common bean. II. Marker-based analysis of morphological and agronomic traits. Crop Sci. 31:23-29.

Singh, S. P., and Miklas, P. N. 2015. Breeding common bean for resistance to common blight: A review. Crop Sci. 55:971-984.

Singh, S. P., and Schwartz, H. F. 2010. Breeding common bean for resistance to diseases. Crop Sci. 50:2199-2223.

van Schoonhoven, A. and Pastor-Corrales, M. 1987. Standard System for the Evaluation of Bean Germplasm. Centro Internacional de Agricultura Tropical, Cali, Colômbia. 